\title{
Leitura do livro organizado por Gustavo Cardoso e Rita Espanha, Comunicação e Jornalismo na Era da Informação (Porto, Campo das Letras: 2006)
}

Felisbela Lopes"

$\mathrm{Na}$ contracapa escreve-se que "o objectivo deste livro é discutir o que caracteriza $\mathrm{o}(\mathrm{s})$ modelo(s) comunicacionais presente(s) (...), compilando os resultados de diversas pesquisas que foram sendo desenvolvidas no quadro do Mestrado de Comunicação, Cultura e Tecnologias de Informação do ISCTE e da Pós-graduação em Jornalismo ESCS/ISCTE». Para esse "estudo da arte” da comunicação e do jornalismo, contribuíram Gustavo Cardoso, Rita Espanha, Daniela Santiago, Eduardo Cintra Torres, Tânia Soares, Susana Santos, Tânia Cardoso, Carlos Cunha, Pedro Pereira Neto, José Pedro Castanheira, Isabel Resende, Luís Proença, Artur Cassiano e Inês Pereira.

O título "revalidar a teoria dos media events" aponta-nos para o decalque das propostas de Daniel Dayan e de Elihu Katz, mas Eduardo Cintra Torres vai muito mais além daquilo que escreveram os autores de La Télévision cérémonielle. O investigador português procura «historizar a teoria das cerimónias mediáticas retrospectivamente, a períodos anteriores à TV e outros mass media» (p. 98). E fá-lo com grande acutilância, invocando períodos recuados da História e desafiando o leitor a estudar certos acontecimentos à luz da teoria dos eventos cerimoniais (p. 101). Na parte final do seu artigo, Eduardo Cintra Torres pensa esta teoria à luz da sociedade mediática que é a nossa, em que "todas as oportunidades para "eventos" em directo são aproveitadas" (p. 109). O investigador fala mesmo em "eventos privados”, aqueles que o canal promove para a respectiva audiência (p. 109), mas, como também se acrescenta a seguir, essa «banalização do conceito de evento no seio da indústria cultural televisiva não deve arrastar consigo a diluição do conceito de media event» (p. 112). O que exigirá certamente uma renovação vocabular. Eduardo Cintra Torres sugere que se substitua a designação de media events/cerimónias televisivas por "cerimónias mediatizadas" (p. 112).

Sigamos, em seguida, para o artigo com o título que se nos afigura mais sugestivo: “A representação da ameaça terrorista na TV portuguesa e o Euro 2004”. Os autores (Susana Santos, Tânia Cardoso, Carlos Cunha e Gustavo Cardoso) escrevem que o seu principal objectivo foi «percepcionar como é que o 11 de Março teve influência na agenda noticiosa do Euro 2004 em Portugal, e se esse acontecimento no país vizinho contribuiu para um aumento das percepções de risco e de ameaça terrorista veiculadas pela TV portuguesa» (p. 157). A competição desportiva foi o enfoque central do Euro 2004, mas em Março (mês dos atentados terroristas de Madrid) 60,6\% do total as notícias que falaram deste assunto fizeram-no através de um enquadramento onde 
se destacavam as questões de insegurança e a ameaça terrorista (p. 160). As fontes de informação foram outro dos vectores em análise. Tratando-se de um evento desportivo, poder-se-ia pensar que os actores do campo futebolístico emergiram naturalmente nas diversas cenas televisivas. Em Março de 2004, os jornalistas preferiram dar a palavra aos políticos, o que é justificado pelos investigadores «não só pela tomada de posição do governo português face aos atentados de Madrid e às possíveis repercussões no plano de segurança interna, mas também pela divulgação e preparação junto do público do próprio evento» (p. 164). Sem que o terrorismo seja «uma condição estrutural da nossa sociedade", o certo é que "a ideia de risco de ameaça terrorista» esteve presente numa parte significativa das peças televisivas relacionadas com o Euro 2004 (p. 170), particularmente aquelas que foram "construídas” em Março de 2004. Tal significa que os atentados de Madrid (que se desenrolaram no plano do real) exerceram uma influência (negativa) nas notícias que antecipavam o Campeonato Europeu de Futebol a realizar em Portugal (construção social da realidade).

Apesar de nem sempre reportar o mais relevante, a televisão pode ter um papel importante no reconforto daqueles que são afectados pelas tragédias humanas. Esta é a tese defendida por Daniela Santiago no artigo intitulado "Tragédia” em que retrata a cobertura televisiva da derrocada da ponte que ligava Entre-os-Rios a Castelo de Paiva em Março de 2001. A investigadora, que é também jornalista, socorre-se de muitos artigos de jornais e de diversas peças televisivas para citar vários jornalistas que fizeram reportagens do que (não) estava a acontecer. Se o pequeno ecrã confere uma dimensão nacional às tragédias humanas, contribuindo assim para um luto colectivo, por outro lado também fomenta um nauseabundo voyeurismo, bem explícito no comportamento daqueles que rumavam até ao local do acidente para olharem o rio onde naufragaram as vítimas.

Da rádio, enquanto objecto de estudo, ocuparam-se Luís Proença e Artur Cassiano. O primeiro para analisar a emissão especial da TSF sobre o pós-referendo em Timor-Leste de Setembro de 1999, o segundo para saber qual a influência do factor tempo nas notícias, nomeadamente nas peças sobre a campanha eleitoral de Junho de 2004 para o Parlamento Europeu emitidas nos noticiários de prime-time da TSF. Antes de se deter na maratona de 390 horas que totalizou a emissão especial iniciada às $19 \mathrm{~h} 00$ horas de 5 de Setembro de 1999 e concluída às 23 h00 do dia 9 de Setembro, Luís Proença explica o conceito de "rádio porta-estandarte", que serve na perfeição para aquilo que foi a TSF nesses dias (pp. 238-244). Explica-nos o investigador que a decisão de fazer este continuum de notícias dedicadas à causa timorense teve em consideração «factores de ordem funcional» (o elevado fluxo informativo proveniente de Timor em tempo de final de férias de Verão dos portugueses e, consequentemente, de carência de notícias), "disponibilidade suficiente de recursos humanos na redacção", "factores de distinção» (a TSF já se havia notabilizado em emissões similares no incêndio do Chiado, na Guerra do Golfo e no bloqueio da Ponte 25 de Abril), "proximidade histórica e afectiva”, razões de “consciência humanista e humanitária» (pp. 246-247). Ao longo das várias páginas do artigo, Luís Proença explica-nos alguns momentos fortes 
dessa emissão: as primeiras cem horas sem publicidades; a concepção dos jingles (por exemplo, “Timor Loro Sae não pode esperar") como instrumento de mobilização das pessoas em torno de uma causa (pp. 255-259); ou o apelo à população para "vestir de branco» (pp. 262-263). Poder-se-ia neste texto dar conta de que não há qualquer reflexão sobre a equidistância que os jornalistas devem manter em relação àquilo que relatam, algo que certamente não esteve muito presente nos dias em análise, mas Luís Proença, logo no início do seu trabalho, diz que não tem "pretensões analíticas de carácter ético ou deontológicas sobre a forma jornalística como se desenrolou a emissão» (p. 237), o que o torna imune a esse tipo de leitura crítica. Um dos factores que se salientaram na emissão especial da TSF sobre os acontecimentos que se seguiram ao referendo em Timor em 1999 foi o tempo. As largas horas de emissão conferiram uma outra grandeza a esta iniciativa da estação privada. E é exactamente o tempo - a duração das peças televisivas - que prendeu a atenção de Artur Cassiano que, parafraseando o conceito de agenda-setting, criou outro de idêntica produtividade significativa: time setting, ou seja, o estabelecimento do tempo, que, na sua perspectiva, «terá um papel importante na configuração da realidade política» (p. 274). Depois de cruzar (as clássicas) referências teóricas na temática que o ocupa (Gurevitch e Blumler, McCombs e Shaw, Tuchman, Schlesinger, Soloski, entre outras), o investigador centra-se nas peças dos noticiários da TSF sobre a campanha para as eleições para o Parlamento Europeu que decorreu em Junho de 2004. Da sua análise, salientam-se os seguintes dados: PS, $\mathrm{PSD} / \mathrm{PP}$ e CDU são, por essa ordem, os partidos com mais tempo de peças noticiosas; $\mathrm{BE}$ e PND têm uma presença residual em antena. Cada partido do primeiro grupo contou com um jornalista a tempo inteiro a acompanhar as suas actividades, mas tal já não aconteceu com o BE e o PND. Significa isso que a composição do alinhamento de um noticiário, pelo menos em contexto de campanha eleitoral, é esboçado muito antes de os respectivos partidos irem para a rua. O que não significa que o repórter seja desprovido de poder de acção. Artur Cassiano invoca outros exemplos para escrever que «é um erro ignorar o papel do jornalista como profissional individual e a sua influência nos conteúdos. Seja no relacionamento que mantém com as fontes, seja na forma como interpreta a realidade» (p. 296).

Aos media tradicionais, este grupo juntou também a Internet como alvo das suas pesquisas. Embora não evidenciando serem acérrimos defensores das teses do determinismo tecnológico, alguns investigadores procuraram perceber o impacte que o universo do on line tem no campo do jornalismo. Uns ficam a meio de caminho, não prescindindo dos media tradicionais com os quais fazem análises comparativas; outros preferiram centrar a sua atenção no ciberespaço e indagar aí as mudanças por que passam os produtores e consumidores da informação (será que este binómio ainda faz sentido a este nível?). Neste plano, um dos textos mais extensos (pp. 19-68) pertence aos organizadores desta obra. Gustavo Cardoso e Rita Espanha procuraram «oferecer ao leitor uma viagem pelo panorama das estratégias televisivas na Internet desde as emissoras europeias até às redes de emissoras norte-americanas e sul-americanas, procedendo à identificação de seis diferentes estratégias televisivas na Internet» (p. 21). 
Os seis modelos são apresentados logo nas primeiras páginas do artigo, num quadro que sintetiza (muito bem) o que vai ser em seguida objecto de análise: Internet de notícias, aprofundamento de notícias, EPG alargado, portal televisivo de conteúdos, portal televisivo institucional e interactividade em rede (p. 28). Umas páginas à frente, Tânia Soares detém-se na relação entre a TV e a Internet, tendo como base do seu trabalho a análise dos sítios da RTP, SIC e TVI, constatando que essas "páginas se aproximam das lógicas de gestão e organização da informação baseada no modelo clássico dos jornais clássicos» (p. 127). O seu estudo remota a 2003, o mesmo ano em que Pedro Pereira Neto estudou os sítios dos diários portugueses generalistas. De então para cá, muito mudou, mas, ao centrar-se nas páginas electrónicas do Correio da Manhã , do Diário de Notícias, do Jornal de Notícias e do Público, o investigador pôs em marcha vectores de análise pertinentes (imediatismo, multimedialidade, hipertextualdiade e interactividade) que ajudam outros a prosseguir idêntico caminho. Se hoje fizesse o mesmo trabalho, Pereira Neto esboçaria outro retrato dos jornais da Internet, mas os elementos que apresenta marcam uma determinada época do jornalismo on line em Portugal. Umas páginas mais à frente, Isabel Resende compara a imprensa tradicional e os formatos exclusivamente digitais do jornalismo económico, detendo-se nos meses de Março e de Abril de 2001. Destes textos, não saem teses muito efusivas relativamente ao impacte da Internet no campo do jornalismo. Talvez porque as empresas de comunicação ainda não descobriram vantajosas oportunidades de negócio neste universo (pelo menos no tempo em que se fizeram estes estudos). O lado dos usuários do on line não é aqui esquecido. José Pedro Castanheira dedicou-se a estudar os comentários feitos pelos leitores do Expresso durante o ano de 2000, constatando que o anonimato reúne uma percentagem alta daqueles que deixam a sua opinião nos artigos em formato digital. Citando Pablo Boczkowski, o investigador fecha o seu artigo com uma pergunta: "o anonimato faz parte da magia ou da maldição da Internet como plataforma de comunicação?”. Aí está uma interrogação a abrir caminhos para outras investigações... 